
tidal influence on selected inland rivers

SUBJECT AREAS:

HYDROLOGY

HYDROGEOLOGY

Received

9 May 2013

Accepted

30 January 2014

Published

26 February 2014

Correspondence and requests for materials should be addressed to A.-E.B. (andreibriciu@ atlas.usv.ro) \title{
across the globe
}

\author{
Andrei-Emil Briciu
}

Ștefan cel Mare University, Suceava, 720229 Suceava, Romania.

The lunar semidiurnal influence is already known for tidal rivers. The moon also influences inland rivers at a monthly scale through precipitation. We show that, for some non-tidal rivers, with special geological conditions, the lunar semidiurnal tidal oscillation can be detected. The moon has semidiurnal tidal influence on groundwater, which will then export it to streamflow. Long time series with high frequency measurements were analysed by using standard wavelet analysis techniques. The lunar semidiurnal signal explains the daily double-peaked river level evolution of inland gauges. It is stronger where springs with high discharge occur, especially in the area of Edwards-Trinity and Great Artesian Basin aquifers and in areas with dolomite/limestone strata. The average maximum semidiurnal peaks range between 0.002 and $0.1 \mathrm{~m}$. This secondary effect of the earth tides has important implications in predicting high resolution hydrographs, in the water cycle of wetlands and in water management.

he lunar tidal influence on inland river streamflow was recently (2010) discovered by Cerveny et al. ${ }^{1}$ and it is imposed by the lunar tidal influence on precipitation. Their study showed the lunar tidal influence on inland rivers only at a monthly scale, but the lunar influence also have a semidiurnal periodicity, best known for oceanic waters.

The inland river levels with daily or shorter periodicities are rarely investigated in the hydrological literature ${ }^{2}$. A recent scientific review (2010) about the daily variations of the groundwater and river levels attributed lunar semidiurnal tidal oscillations (M2) only to groundwater ${ }^{2}$ while the semidiurnal fluctuations in rivers were not mentioned. A diurnal fluctuation of the stream water level exists and, when it is strong enough to be detected and measured, it is attributed to freezing/thawing, rainfall, temperature-dependant streambed hydraulic conductivity, viscosity of water, infiltration, evaporation, evapotranspiration and, on impaired rivers, to human intervention ${ }^{2-4}$. The semidiurnal fluctuations of inland streamwater level is almost an unexplored domain; these fluctuations have the form of a daily double-peaked evolution of the gauge height/discharge and are generally considered to be transient and caused by stormwater runoff, unphased local processes or snowmelt characteristics ${ }^{5}$.

The tidal force creates the earth tides. According to Lambert ${ }^{6}$, in 1880 Grablowitz attributed the semidiurnal fluctuations in wells to the tidal forces with the mention that there is an inverse relationship in mid-continental areas between water level and tidal force; later studies confirmed this idea ${ }^{7-9}$. The semidiurnal fluctuations of the groundwater level is attributed to the elastic storage coefficients of the geological strata and the compressibility of solids under tidal force and to the tidal dilatation of water filled finite cavities (fracture, matrix, open joints between strata $)^{10-13}$. The different compressible rocks create a horizontal hydraulic gradient which induce horizontal groundwater movement as response to the variations of the tidal force $\mathrm{e}^{14}$.

It was discovered that confined conditions can be found very close to the topographic surface and it was hypothesized that this affects shallow flow processes and the generation of surface streamflow ${ }^{15}$. One of the effects is that an aquifer will respond to the tidal pressure change with the outflow and/or the inflow, as already theoretically stated ${ }^{16,17}$.

The hypothesis to be tested in this article is that the Moon tidally affects the water level of non-tidal rivers with a M2 signal by acting through earth tides on groundwater. We named this effect "orthotidal" in order to distinguish it from the lunar effect on tidal rivers through the oceanic tides. Because the fluctuation of the groundwater due to Moon is few centimetres or millimetres height range, we supposed that the possible river level fluctuations due to discharge from tidally affected aquifers must be centimetres or less range. At the mid-continent groundwater sites, the M2 signal of tidal forces is strongly dominant ${ }^{18}$ and should be first detected if there are any orthotidal signals in rivers. Even if the barometric pressure of the atmospheric tides is taken into account to estimate 
Table 1 | Details of the primary gauges

\begin{tabular}{|c|c|c|c|}
\hline no. & Code and name & a.s.l. $(\mathrm{m})$ & ampl. $(\mathrm{m}) *$ \\
\hline 0 & USGS 02306028 Hillsborough Rv. at Platt Street at Tampa, FL, USA & 0 & 0.6 \\
\hline 1 & 219003 Bemboka Rv. at Morans Crossing, NSW, Australia & 95 & 0.1 \\
\hline 2 & USGS 08203450 Leona Rv. at CR 429A nr Uvalde, TX, USA & 320 & 0.01 \\
\hline 4 & USGS 08068450 Panther Br. nr Spring, TX, USA & 30 & 0.02 \\
\hline 5 & USGS 07060500 White Rv. at Calico Rock, AR, USA & 90 & 0.1 \\
\hline 6 & USGS 06893100 Blue Rv. at Kenneth Rd, Overland Park, KS, USA & 220 & 0.01 \\
\hline 9 & USGS 08456300 Las Moras Springs at Brackettville, TX, USA & 320 & 0.1 \\
\hline 10 & USGS 07311630 Middle Wichita Rv. nr Guthrie, TX, USA & 470 & 0.01 \\
\hline 11 & 219018 Murrah Rv. at Quaama, NSW, Australia & 150 & 0.003 \\
\hline 12 & USGS 08190000 Nueces Rv. at Laguna, TX, USA & 300 & 0.005 \\
\hline 13 & USGS 50834035001 Rio Sico at Barranco Blanco, Honduras & 415 & 0.03 \\
\hline
\end{tabular}

groundwater level fluctuations ${ }^{13}$, it doesn't have significant semidiurnal effect on groundwater level compared to the earth tides ${ }^{14,19}$ and it will probably not be detected in rivers.

\section{Results}

We analysed river level data from water level monitoring gauges with long time series (1-24 years) and high accuracy (1-3 mm, measured every 15-60 minutes) from USA, Honduras and Australia. The first selection of these sites was made by choosing the gauges having constant double-peaked daily evolution during 7 consecutive days in June-July 2011 (7 consecutive days represent the standard analysis window for fast graphical preview of the websites providing our data). Summer in the northern hemisphere is winter in the southern hemisphere. For example, the climates of Canberra (Australia) and San Antonio (Texas) are very different: the higher air temperatures and precipitation amounts occur during November-April in Canberra and during May-October in San Antonio. Also, in the same hemisphere, summer months mean different air temperatures and amounts of precipitation and greatly varying temporal distribution of the annual peaks of these parameters. The vast territories of USA, Australia and Honduras (used for selecting data) and the very large distances between the selected gauges provided a wide diversity of climates. Thus, the worldwide selection of sample gauges in a given month/group of months (without using discriminative/subjective criteria such as season, temperature, precipitation) is an unbiased sampling and must, in theory, prove the omnipresence of the semidiurnal signal if this is found to be worldwide spread. A number of 2000 USGS streamwater monitoring sites placed on non-tidal rivers in USA were searched in the states covering the following aquifers: High Plains, Edwards-Trinity, Mississippi Embayment-Texas Coastal Uplands, Coastal Lowlands, Piedmont and Blue Ridge. These representative aquifers were chosen in order to discover their possible tidal input in rivers. The streamwater level was also analysed for sites from New South Wales and Queensland (250 monitoring sites each one, from the Australian governmental monitoring network), especially in the Great Artesian Basin area. The gauge heights in Honduras (USGS network) were searched in order to observe if a different climatic influence on rivers affect the intensity of the possible semidiurnal signal. All analysed gauges had varying types of climate, from continental or humid temperate to subtropical and humid tropical.

139 gauges were preliminary selected as possibly having a constant M2 signal. Then, the gauges with persistent (120 days) doublepeaked daily evolutions were selected for a Fast Fourier Transform (FFT) analysis (120 days of samples per station, one sample per hour, 30 minutes or 15 minutes, depending on gauge - we considered that $1 / 3$ of a year is sufficiently long to provisionally decide if a signal is persistent or not to provide relevant data for further analyses). The FFT analysis permitted the identification of rivers with semidiurnal signal stronger than the surrounding red noise. Also, a satellitary analysis of each catchment was performed by using $2.5 \mathrm{~m}$ resolution SPOTImage imagery in order to discover and eliminate the rivers with major human interventions on river discharge. A final list containing 13 relevant gauges resulted (Table 1, no. 1-13). The selected river gauges were chosen as representative if they had strong semidiurnal signal and if the USGS site description was generally: "records well, no dam or deviation". Even if half of the remaining gauges/catchments have some human intervention, we kept them because the intervention is not considered important and because the rivers showed relevant results at the later statistical analysis. Few remaining gauges have dams in their upstream catchments but, according to Zimmerman et al. ${ }^{20}$, the subdaily oscillations in rivers with dams do not greatly differ from the natural oscillations in rivers. Therefore, the human intervention is not considered important when the semidiurnal signal is very strong and the human influence (diversion, dam) is singular and not of large impact.

In order to successfully detect the orthotidal behaviour in the selected rivers, the semidiurnal signal was compared to that of Hillsborough River, Florida (no. 0, control gauge), which is a representative tidal river. According to USGS, "the gauge height at this site is significantly affected by astronomical tides" and the river periodicities show a very strong and dominant M2, having typical semidiurnal tides, with two high and two low waters per day. All river gauges have 96 measurements per day ( 1 measurement per 15 minutes), excepting gauge no. 10 ( 1 measurement per 30 minutes). The majority of the selected time series ranges from Oct. 2007 to Feb. 2013, excepting no. 2 (Oct. 2009-Aug. 2011), no. 10 (June 1994-Oct. 2006), no. 11 (May 2009-July 2011) and no. 13 (Nov. 2012-Feb. 2013).

The continuous wavelet transform (CWT) analyses of the selected gauges showed semidiurnal periodicities with 0.95 confidence level against red noise for long time intervals in some time series when the analysis window was set for the entire length of data (Figure 1, a-f; Supplementary Fig. 1, a-h). On scalograms, the semidiurnal signal is to be found in the $0.3-0.6$ days periodicities band of the vertical axis; on this band, the intensity of the signal (blue - minimum, red maximum) varies regularly or irregularly from the beginning to the end of the time series depending on the importance of the generating and erasing factors. As it can be observed in Figure 1.d, the change in gauge height characteristics due to monitoring interventions has modified the accuracy of the semidiurnal signal. Moreover, for all full-length data scalograms, the consequences of high waters on smaller signals can be observed: the vertically elongated highpower and non-red noise areas, in opposition to the horizontally 
a

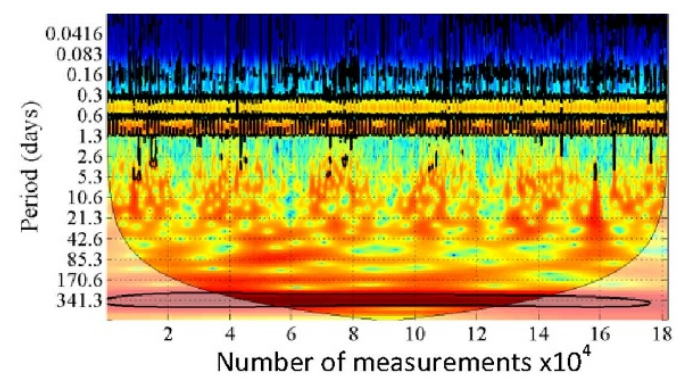

b

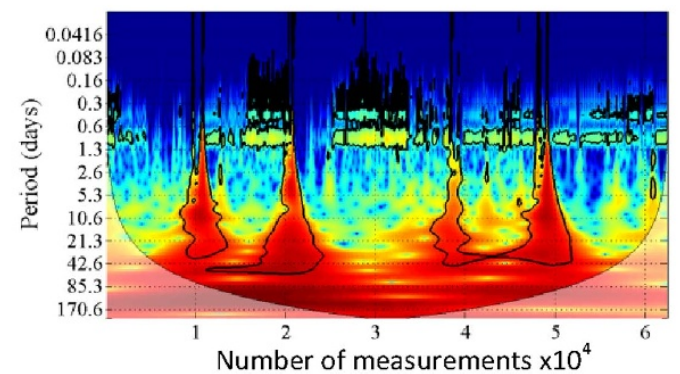

C

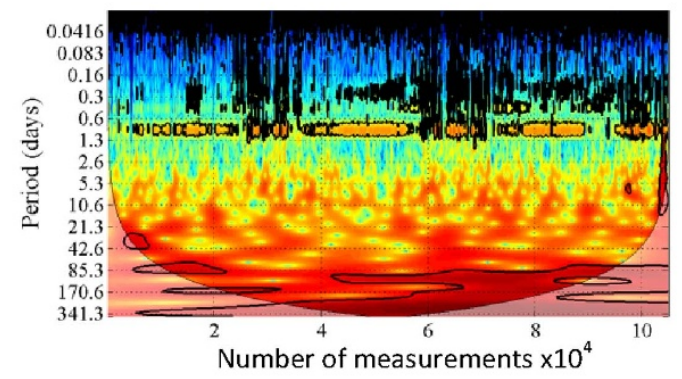

d

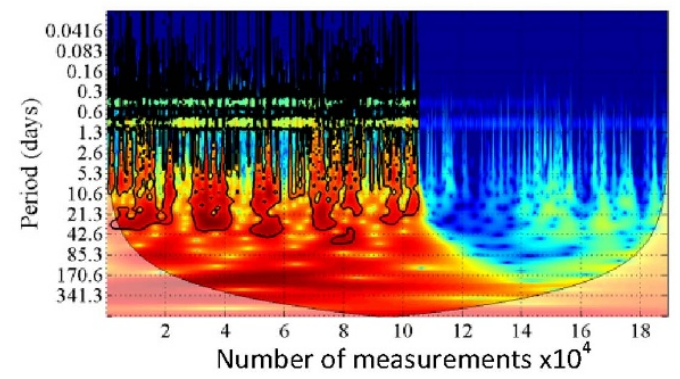

e

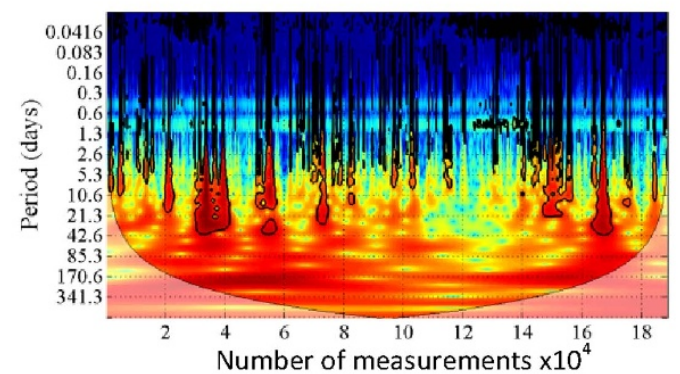

$\mathrm{f}$

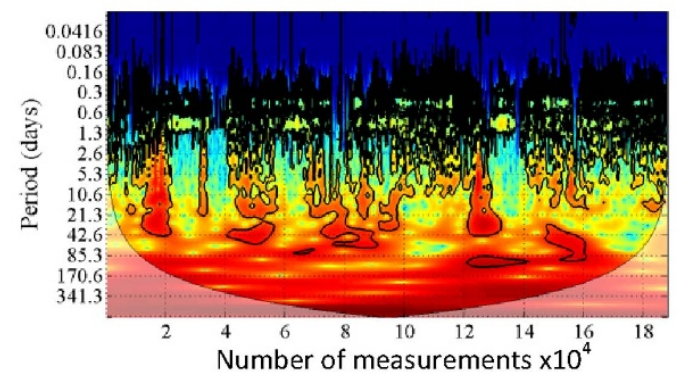

g

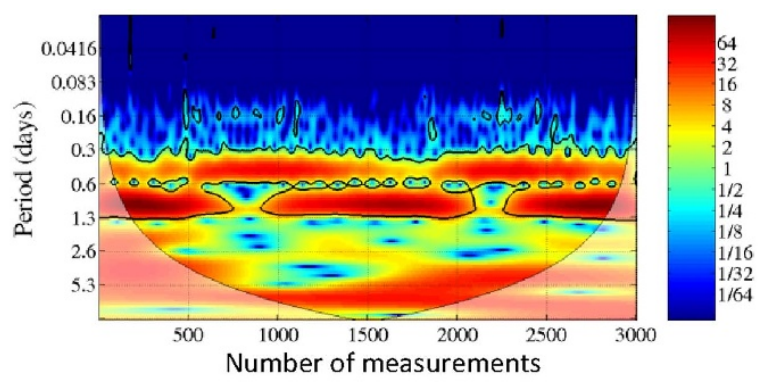

h

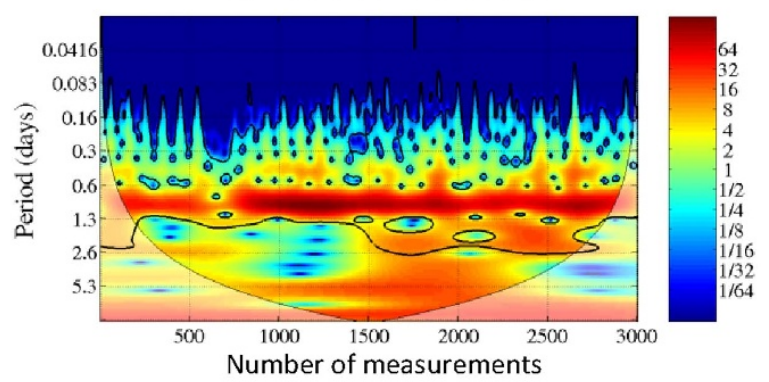

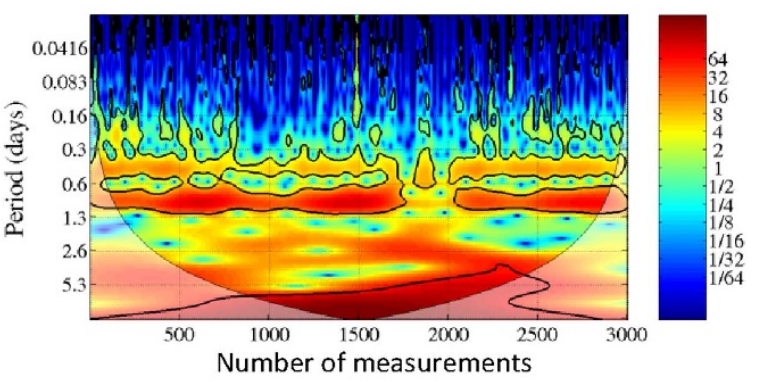

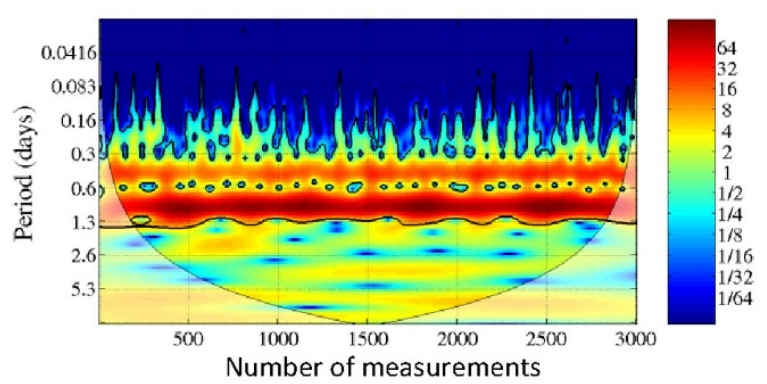

k
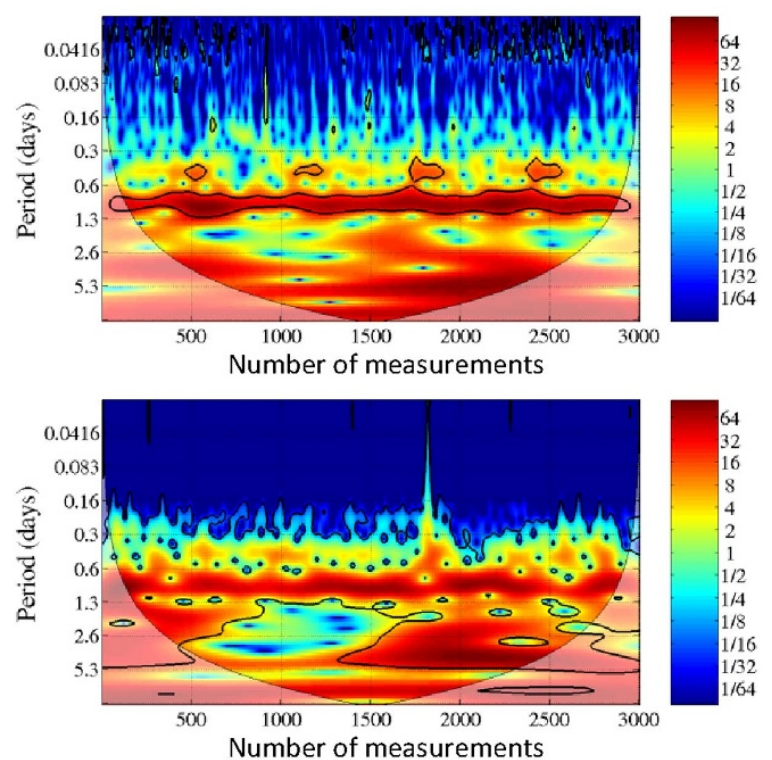

Figure 1 CWT scalograms: (a-f) - of the time series no. 0-5 from Table 1 (the horizontal axes represent the number of consecutive measurements, 96 per day); (g-l) - of selected 3000 consecutive measurements from the time series no. 0-5 from Table 1; the thick black contours represent the 0.95 confidence level against AR1 red noise; the colours with lighter shade of the power spectrum represent temporal areas affected by edge effects. 
a

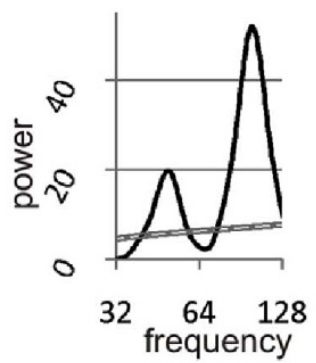

$\mathrm{C}$

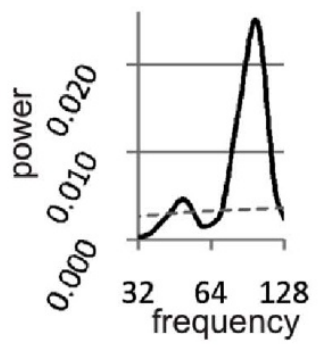

e

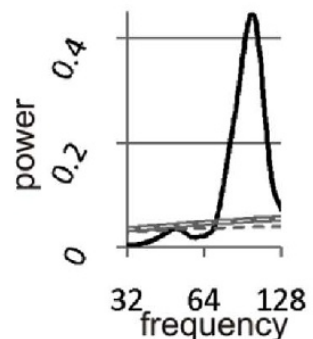

GWS -... 0.67 confidence level b

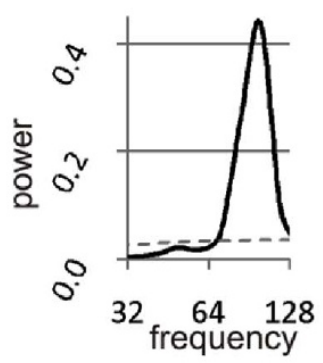

$\mathrm{d}$

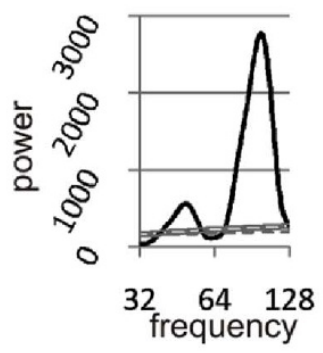

f

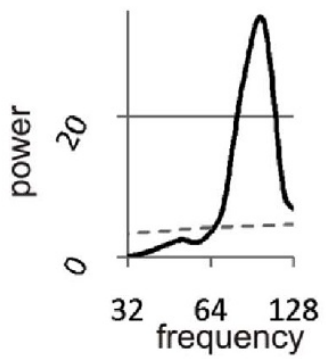

Figure $2 \mid$ Periodograms of the time series no. 0-5 from Table 1, extracted from Figure 1.g-1 scalograms (the frequency represents cycles per number of measurements).

elongated high-power and non-red noise areas of the diurnal and semidiurnal signals.

We observed that the CWT analysis is more relevant for full time series without important episodes of high waters and for smaller time intervals, between high waters. When the CWT analysis is applied for shorter time series ( 3000 consecutive measurements per gauge), that do not include the high waters episodes and their disturbing effect, the power and the statistical relevance of the semidiurnal and diurnal periods increase. All selected gauges, when analysed for shorter time series, show semidiurnal signal with 0.95 confidence level against red noise. Much shorter time series will not have enough length to reveal the high statistical relevance of the semidiurnal signal. The CWT analyses of the shorter time series (Figure 1.g-l; Supplementary Fig. 1.i-p) include the most representative time intervals from the full-length data scalograms (the intervals with the greatest power of the semidiurnal signal). These scalograms show wider areas of the semidiurnal signal with 0.95 confidence against red noise (especially due to a diminished number of high waters episodes); these areas also have an enhanced power of the signal (red-shifted colours that indicates higher amplitudes and/or a more regular behaviour of the semidiurnal signal).

The global wavelet spectrum (GWS) is extracted from the scalograms of the shorter time series; on the resulted periodograms (Figure 2, Supplementary Fig. 2), the daily peak (diurnal oscillation) is visible as the main peak, while the semidiurnal peak is lower, having confidence levels from above 0.95 to under 0.67 . The semidiurnal signal of inland rivers has the same wavelength as the semidiurnal signal of the tidal control gauge (M2): 12.42 hours (49.689 measurements).

For inland rivers, the diurnal peak has a relatively stable hourly position, while the semidiurnal peaks are very mobile. The semidiurnal peaks often have repeating positions after a number of days or split the diurnal peak in 2 peaks with evolving and repeating shapes; sometimes, the M2 signal do not have enough power to create distinct peaks, but only to impose inflections on the ascending or descending slope of the diurnal peak (Figure 3.a-f; Supplementary Fig. 3.a-h). During and after strong rains, easily identified through the sudden increase of an asymmetrical high water peak, extending on multiple days, the semidiurnal signal is temporarily erased.

For inland groundwater, M2 is followed by the much weaker K1 and $\mathrm{O} 1$ lunar diurnals and the rivers do not show them; a solar semidiurnal S2 signal is, generally, the second strongest signal in groundwater ${ }^{18}$ and is caused by the solar tidal force. The GWS of the partial wavelet coherence (PWC) analyses (wavelet coherence between M2 or S2 sine waves and the river time series without S1 (solar diurnal) sine wave - S1 is extracted in order not to alter the results of the wavelet coherence analysis) clearly shows that the semidiurnal signal in the studied rivers is to be attributed to M2 (which has higher power), not to S2 (Figure 3.g-l, Supplementary Fig. 3.i-p).

The disturbing effect of high waters and red noise on M2 signal can be partly removed by obtaining a simple derivative (difference between neighbour values) from the water raw data. The new data can enhance signal detecting in simple plots (Figure 4) and scalograms (Figure 5) or can cause an important reduction in the confidence level against red noise (Figure 6) because of the increased data artificialization. Therefore, the results of the derivative method are to be used with precaution. In some cases, the differencing of the neighbour values alters the slope of the semidiurnal inflections when these are transformed into peaks by reducing their angles and this translates into weaker semidiurnal signal in the wavelet analysis.

The M2 semidiurnal oscillation in the studied rivers is caused by the M2 signal in the regional aquifers. Examples are Leona River near Uvalde, where the semidiurnal oscillation is stronger when it is also stronger in the Mc Knight Formation below (for example, in the piezometer placed $10 \mathrm{~km}$ E of upper Leona streambed), part of Edwards-Trinity aquifer (Figure 5). This local behaviour of the Edwards-Trinity aquifer system is not an exception, being found in many other wells. The other aquifers related to the studied river gauges have M2 signal too, for example the Evangeline aquifer (part of the Gulf Coast aquifer, which is included in the Coastal lowlands aquifer system) (Supplementary Fig. 4) - the Evangeline aquifer provides water for Panther Brook at Gosling and the Conroe piezometer is placed $15 \mathrm{~km} \mathrm{~N}$ of the river gauge.

We searched if a strong and persistent M2 signal in local aquifers can be used as detector of rivers with a same type oscillation. For this case study, in the USGS water data network, we used only the Edwards-Trinity aquifer system. The amplitude of the M2 groundwater oscillation in USGS 295204099340201 AS-69-12-206 (upper Medina River catchment) is probably the most important in this aquifer. The M2 signal is much stronger than the diurnal one and has 2 peaks per synodic month, linked to the New and Full Moon (Figure 6.a,b). There is a good correlation between the groundwater in the mentioned piezometer and the Medina River at San Antonio gauge, the weaker or stronger semidiurnal signals appearing in groundwater-river pairs; however, it seems that the two M2 signals are in anti-phase (Figure 6.c). The M2 signal of Medina River is strongest at San Antonio gauge; it is weaker than the diurnal signal but, at a medium size analysis window (5 months) it shows 4 peaks of statistical power and 0.95 confidence level against red noise per synodic month (Figure 6.d-g). These peaks are probably related to the Moon phases.

The correlation between the river gauge height and groundwater level has many statistical relevancies depending on the indices and methods used. For example, the simple Pearson, Kendall and 
a

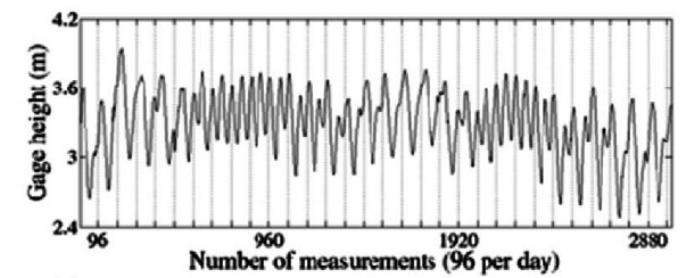

b

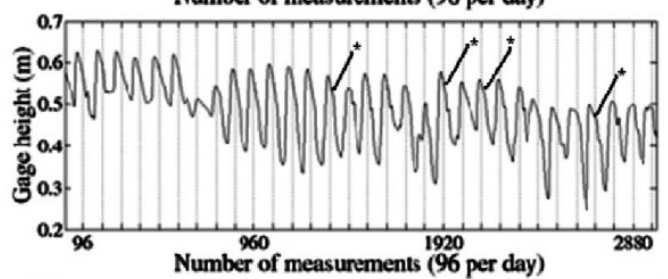

c

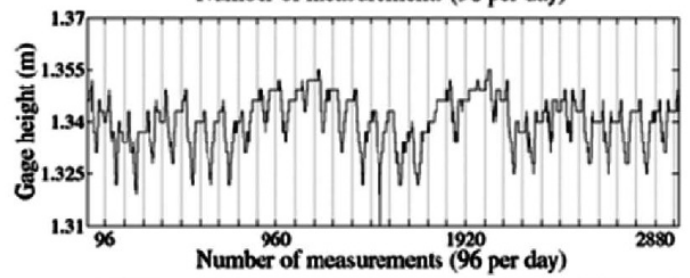

d

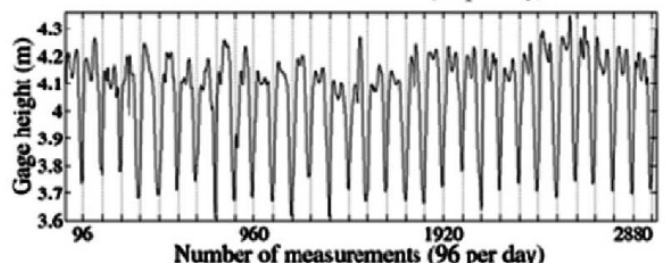

e

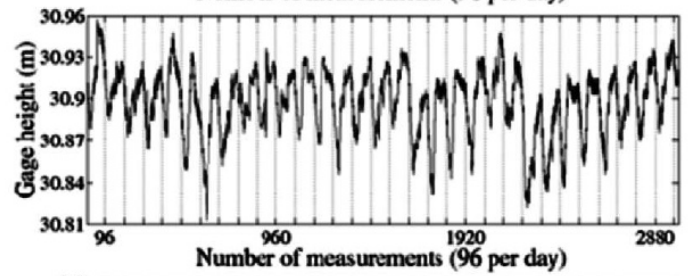

f

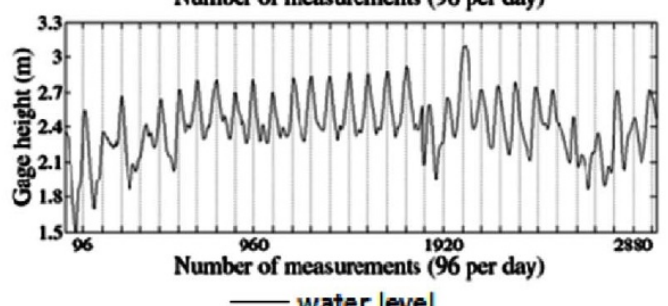

g

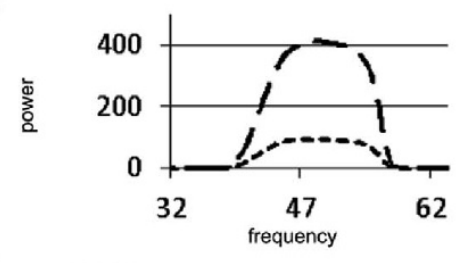

h

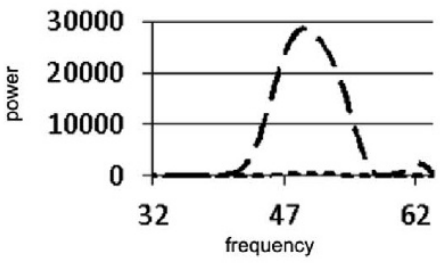

i

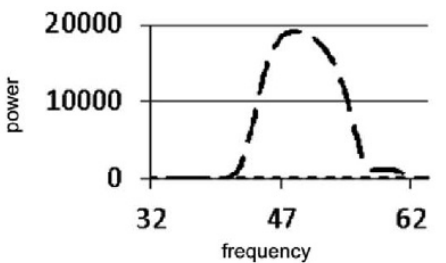

j

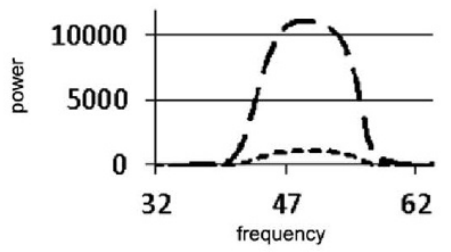

k

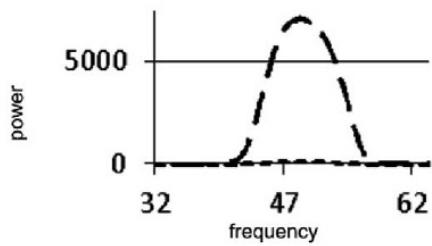

I

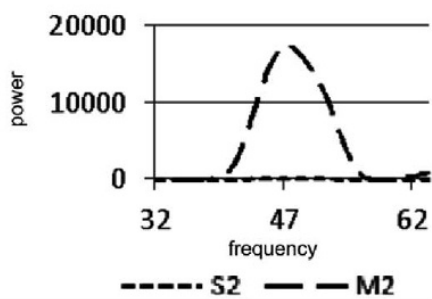

Figure 3 Selected short time series extracted from the time series no. 0-5 from Table 1 (a-f); periodograms of the GWS values extracted from PWC scalograms of the a-f time series ( $\mathrm{g}-\mathrm{l})$ (the frequency represents cycles per number of measurements; *-examples of M2 inflections).

Spearman correlation coefficients between Medina River and Edwards piezometer show medium or weak correlations in JuneAugust 2013 (Table 3). A scaled correlation using the same types of correlation coefficients indicates a stronger correlation. The scaled correlation is obtained here by correlating parameters for each 24 hours consecutive window. The scaled correlation method generates daily correlation coefficients (Figure 7.a) which are averaged to obtain the scaled correlation coefficient (Table 3 ). The daily correlation coefficients generally show good negative correlations (Figure 7.a) and the scaled correlation coefficient is altered by the minority of days having weak or no correlations.

A more reliable method to identify the strong and real correlation between 2 nonlinear signals in river/groundwater time series is the wavelet coherence analysis (WTC - method used to find similarities between signals/wavelets with changing time lags ${ }^{34}$ ). On scalograms in Figure 7.b-e the wavelet analysis identifies with a black line the areas where the two signals have a common evolution with a 0.95 confidence level against casual common evolution (by using a Monte Carlo test). The similarities between common signals in 2 time series is also indicated by the high/low power colours. The WTC scalograms of Medina River and Edwards piezometer show a good correlation of the semidiurnal signals. The same type good correlation exists between the semidiurnal signal in the other studied rivergroundwater level pairs (Supplementary Fig. 5).

The good correlation between the presence/absence of the M2 signal in groundwater and rivers is valid for Australia, too. The Ranch piezometer in Bega catchment (which includes the previously studied Bemboka and Murrah rivers) shows good M2 signal (Supplementary Fig. 6). By searching the piezometers in the springs cluster area of the Great Artesian Basin, Macquarie River Basin, we discovered a very good M2 signal in Trangie piezometer (Figure 8.a,b). The Trangie piezometer is placed in Bogan River 


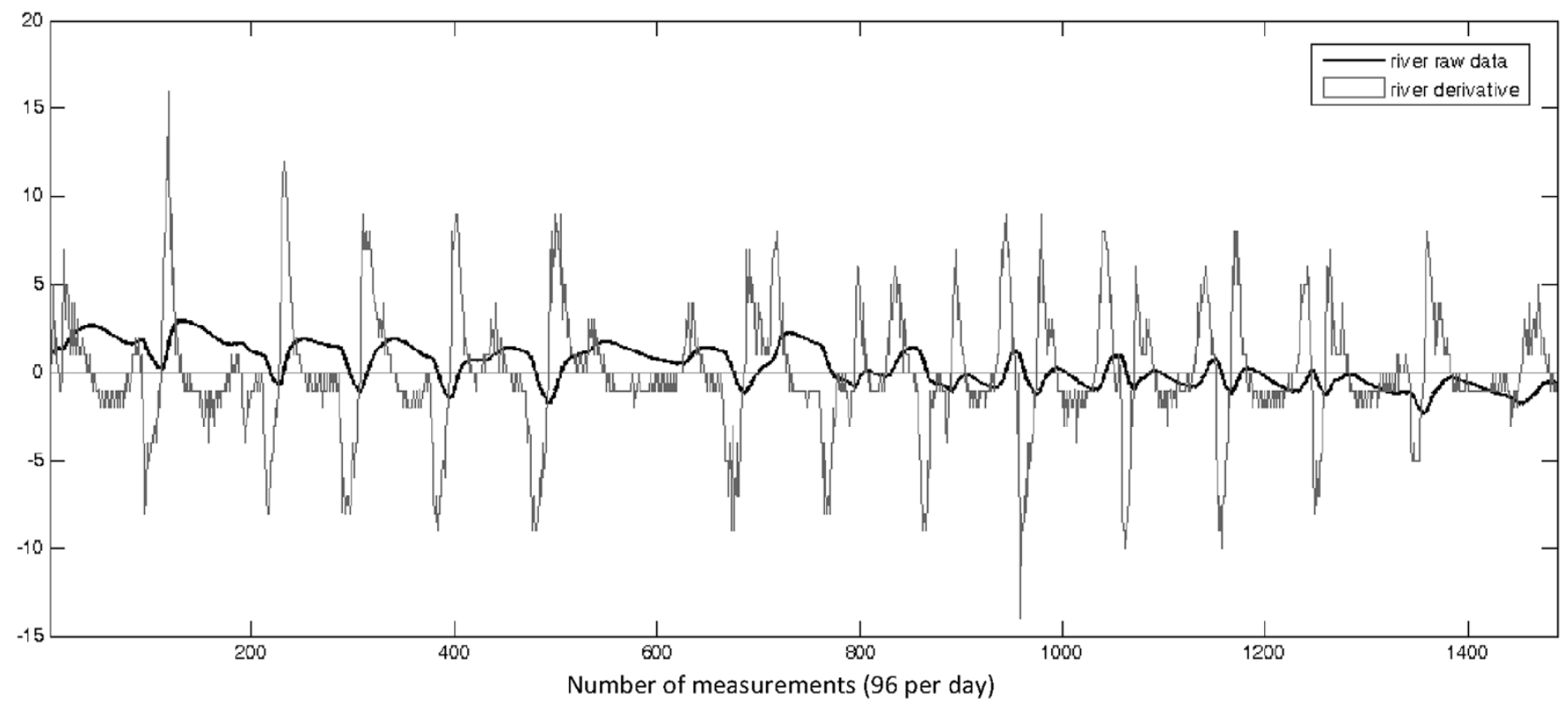

Figure 4 - Comparison of the M2 semidiurnal signal in raw data and simple derivative data of Bemboka River at Morans Crossing during the first half of October 2009 (the vertical axis represents normalised flow values for the river raw data and the difference between neighbour values *1000 for the simple derivative data).

catchment. Bogan River has M2 signal, but only in the area near Trangie piezometer: the signal appears at Dandaloo gauge, becomes strongest at Neurie Plains gauge and fades at Nyngan gauge (Figure 8.c-j); the other upper and lower gauges, which are placed outside the springs cluster area, do not show the lunar semidiurnal signal. The WTC analysis of the river-groundwater pair in Bogan River catchment also show a good common evolution of the semidiurnal signal (Supplementary Fig. 7).

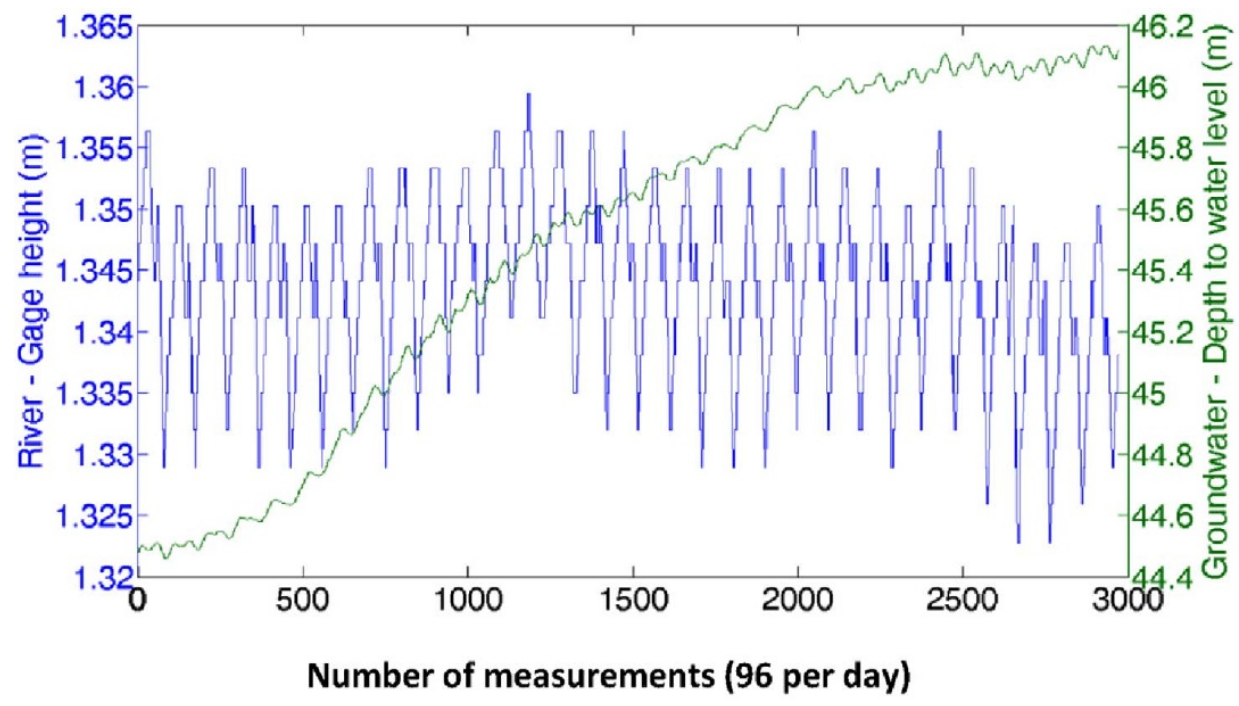

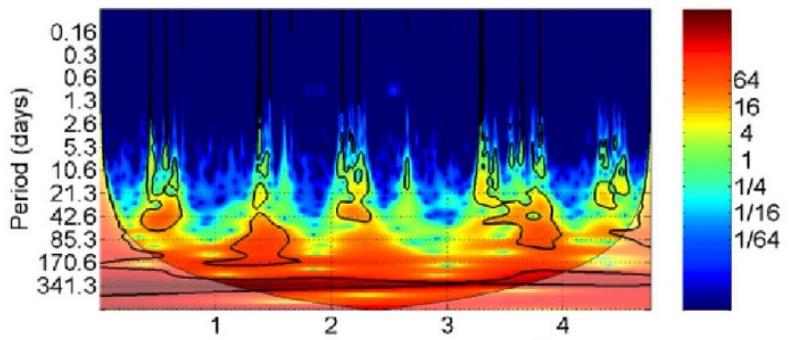

Number of measurements $\times 10^{4}(24$ per day)

b a

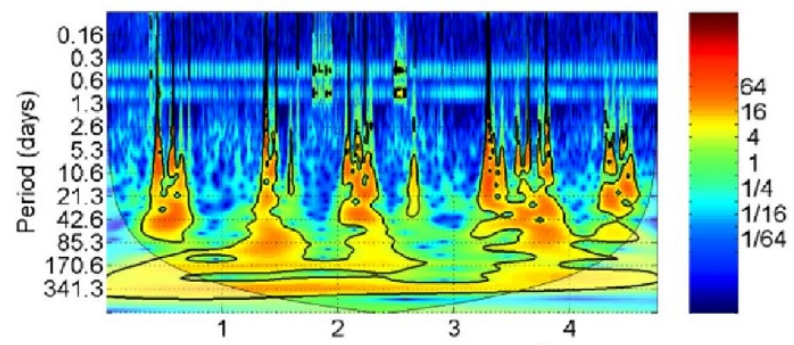

Number of measurements $\times 10^{4}(24$ per day)

c

Figure 5 The presence of the M2 signal in Leona River and Uvalde piezometer: (a) - the good graphical correlation between the peaks and valleys of the M2 signal in river and groundwater in August 2011; (b, c) - scalograms of the Uvalde piezometer during October 2007-August 2013 for raw data and, respectively, simple derivative data. 


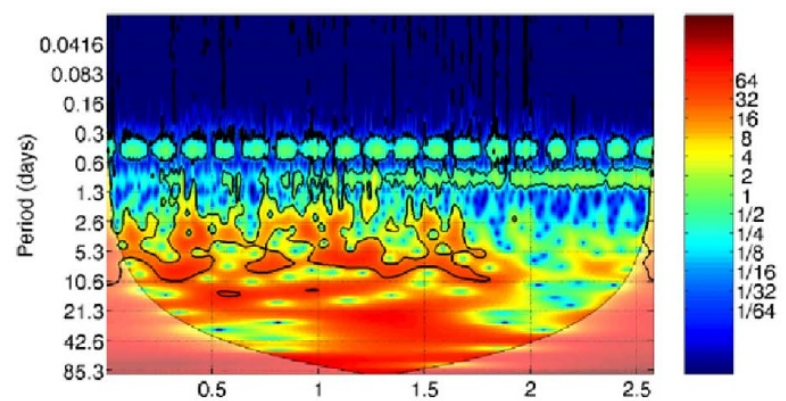

Number of measurements $\times 10^{4}$ (96 per day)

a

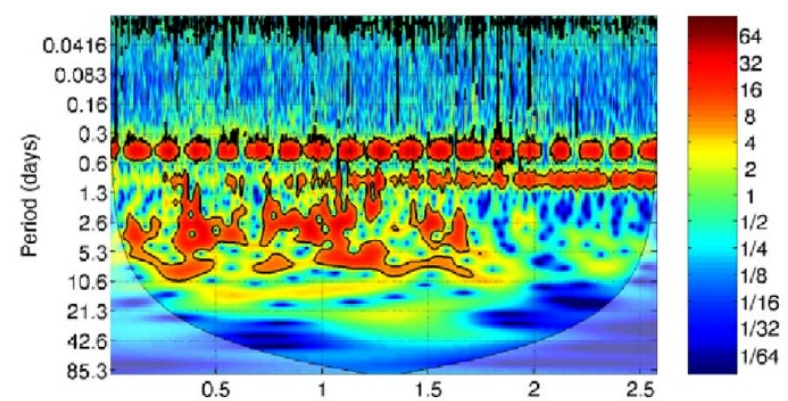

Number of measurements $\times 10^{4}$ (96 per day)

b

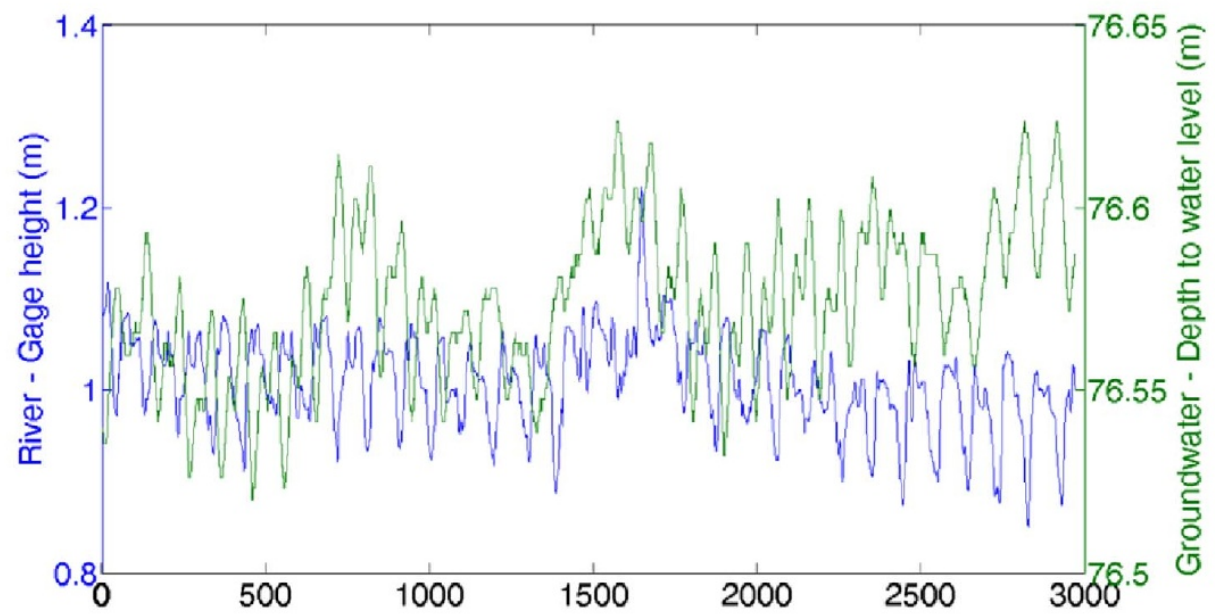

Number of measurements (96 per day)

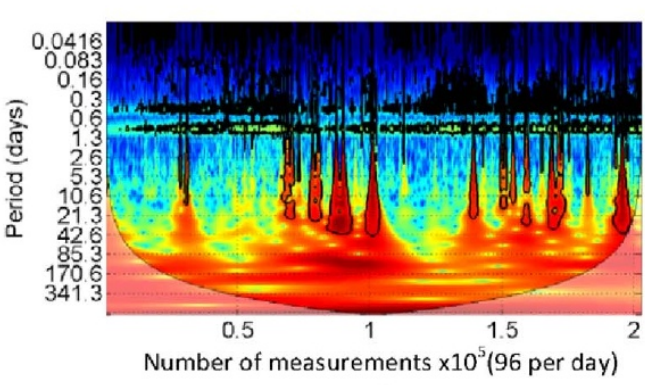

d

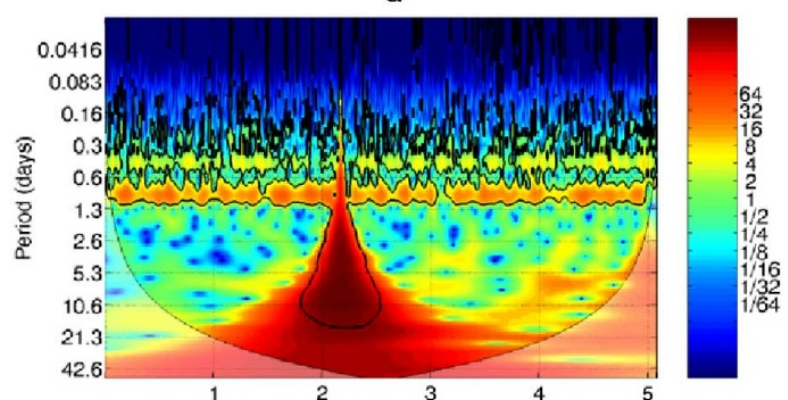

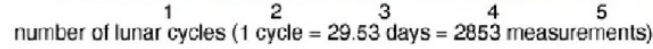
$f$

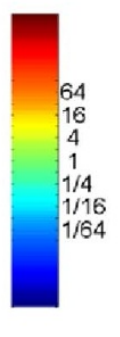

C

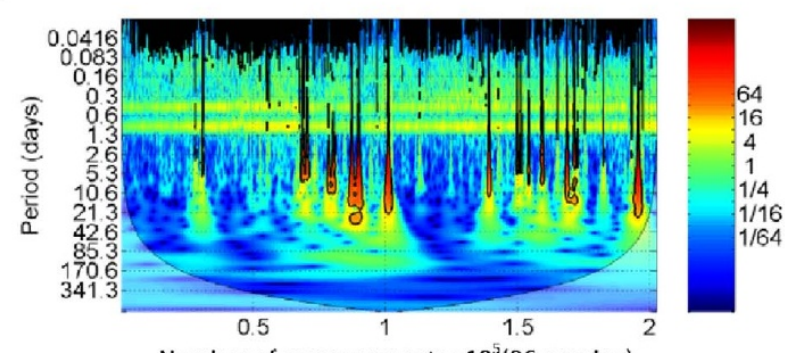

Number of measurements $\times 10^{5}$ (96 per day)

e

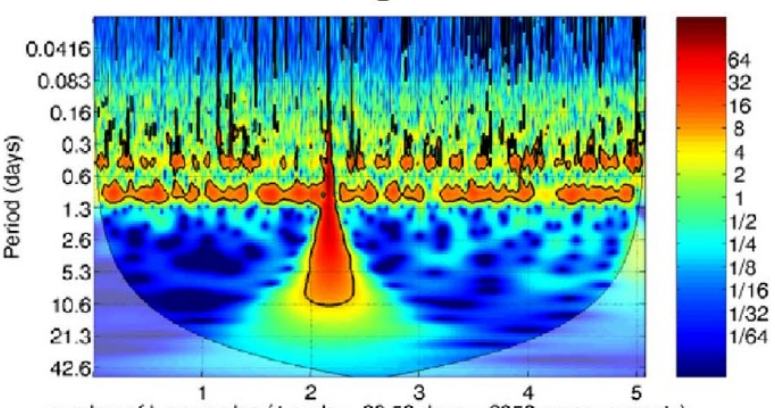

number of lunar cycles $\stackrel{1}{2} \underset{\text { cycle }}{2}=29.53^{3}$ days $=2853^{4}$ measurements $)$

$\mathrm{g}$

Figure 6 The presence of the M2 signal in Medina River and Edwards piezometer: $(a, b)$ - scalograms of the Edwards piezometer during October 2007-August 2013 for raw data and, respectively, simple derivative data; (c) - the graphical correlation between the peaks and valleys of the M2 signal in river and groundwater in July 2013; (d, e) - scalograms of the raw and, respectively, simple derivative time series of Medina River during October 2007-August 2013; (f, g) - scalograms of the raw and, respectively, simple derivative time series of Medina River during November 2012-April 2013. 


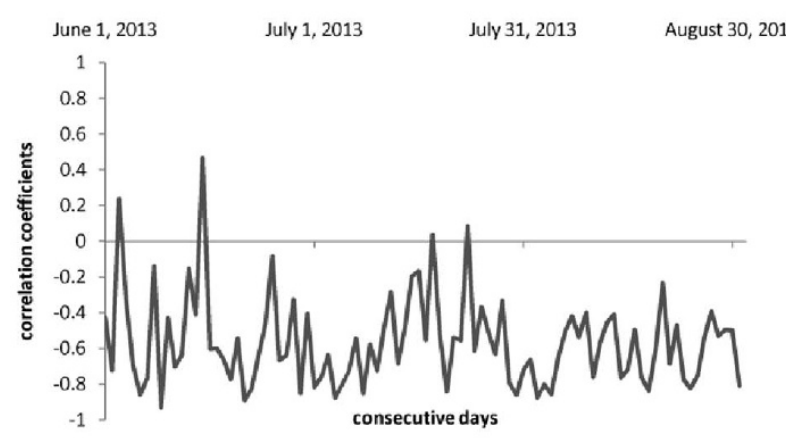

a

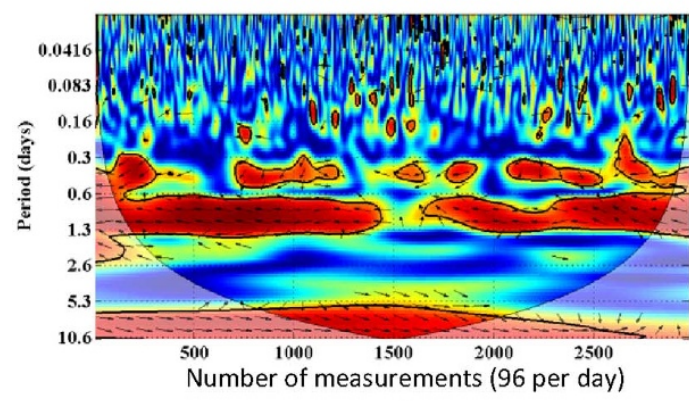

C

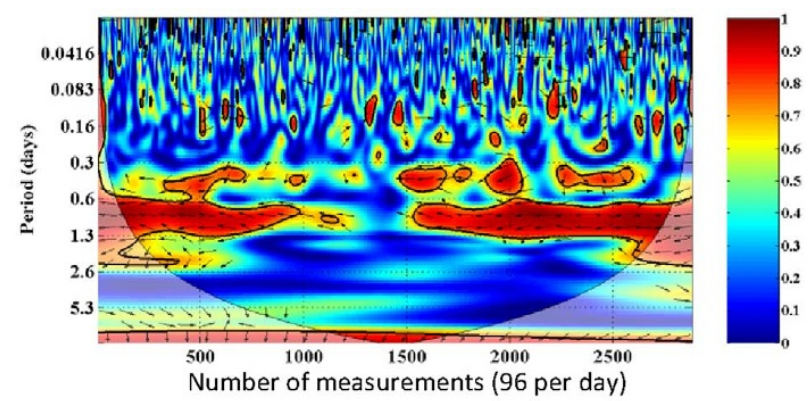

b
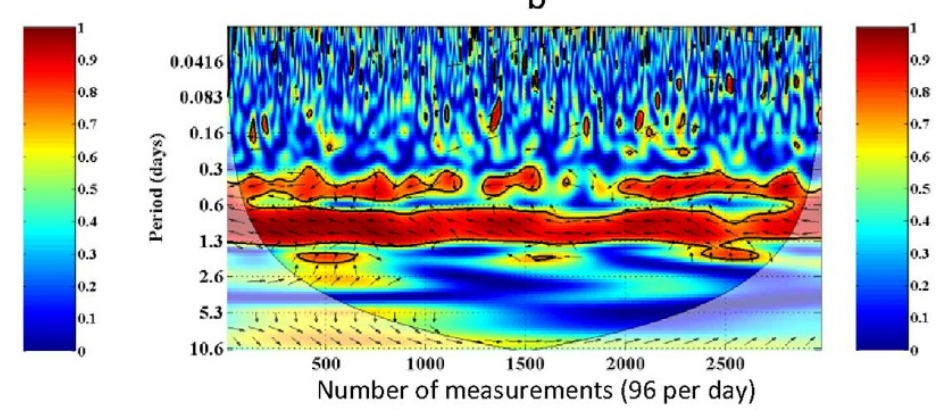

d

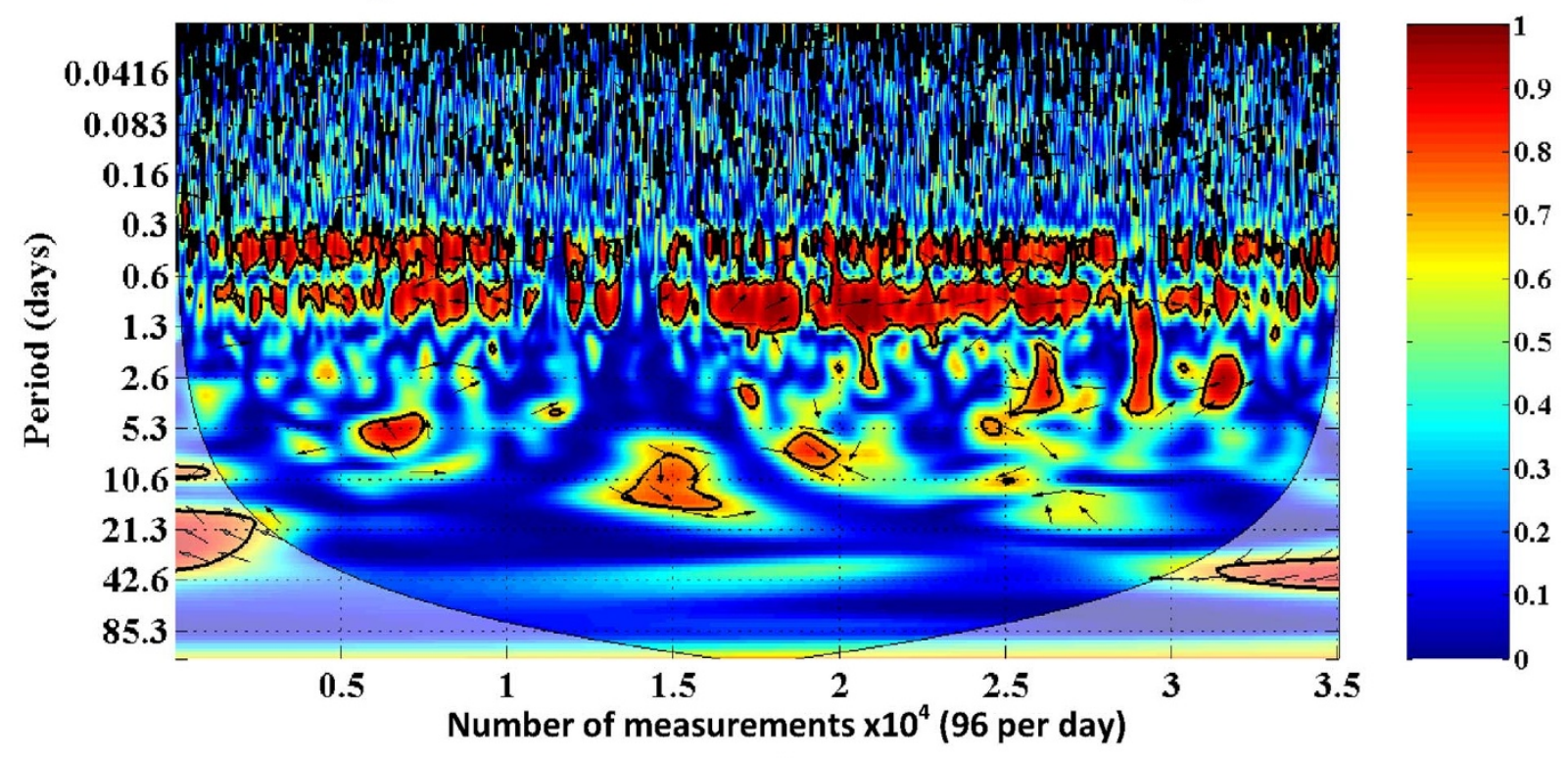

e

Figure 7 | Examples of correlations between Medina River at San Antonio gauge and Edwards piezometer (raw data): (a) - daily Pearson correlation coefficients; (b) - June 2013 WTC; (c) - July 2013 WTC; (d) - August 2013 WTC; (e) - January-December 2013 WTC.

For improving the statistical relevance of the M2 orthotidal signal in inland rivers, longer time series are necessary. Therefore, USGS archives data were added to the existing time series in order to obtain longer time series. The maximum length obtained per each gauge is equivalent to the period of the continuous 15-60 minutes measurements. The particular maximum length is of 24 years for Medina River. However, not all gauges time series were extended. The selected gauges on Leona and Comal rivers are newer than 2007, while the gauge on Middle Wichita River was discontinued in 2011. The extended time series are available in Figure 9 and Supplementary Fig. 8. Note that that the USGS archive was stored as river discharge, not river gauge height. Also, older data frequently have only hourly measurements (not for every 15 minutes). Therefore, the entire longer time series were transformed into hourly discharge data (by averaging, when necessary). For the Australian gauges (NSW Water Information), river data older than 3-4 years is very discontinuous and irregularly sampled and was not used to expand the existing time series. But, as it can be observed in Supplementary Fig. 9, for the same time period, the discharge data is less relevant than the gauge height. The most important factors contributing to that difference are: the diminishing importance of the very small water level oscillations in the used discharge formulae, the USGS data storing method (no decimal for discharges greater than 10 cubic feet per second, 1 decimal for discharges between 1 and 10 cubic feet per second and 2 decimals for discharges less than 1 cubic foot per second) and the frequently changing riverbed morphology (that continuously alters the discharge formulae, while the gauge height is altered discontinuously rather than in a continuous manner). Even if the USGS data is more continuously and regularly sampled than the Australian river data, the standard USGS gauge height increment is of only 0.01 feet $(\sim 3 \mathrm{~mm})$, while the similar Australian increment is of $1 \mathrm{~mm}$. This probably explains the smaller 

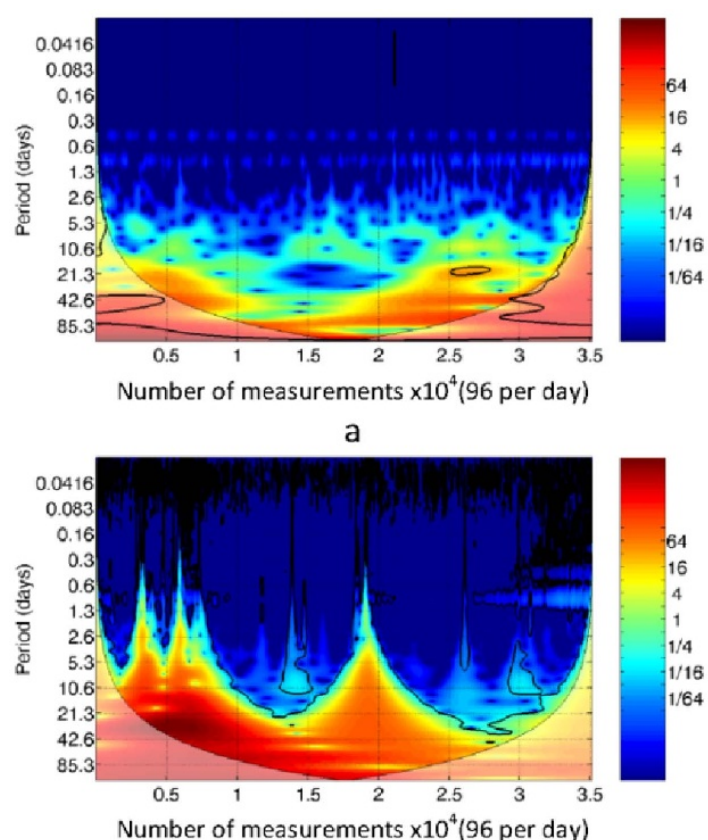

C
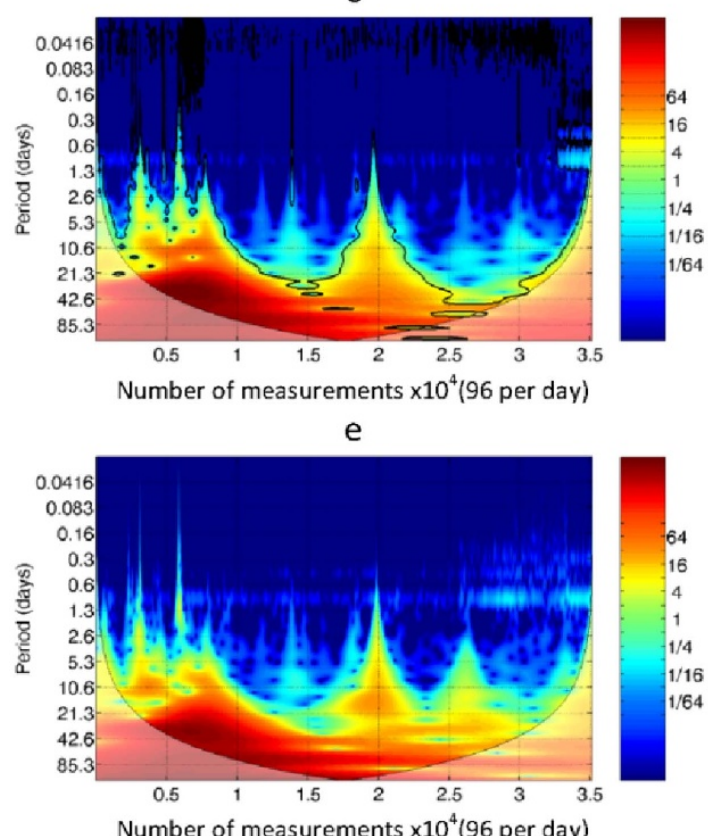

g

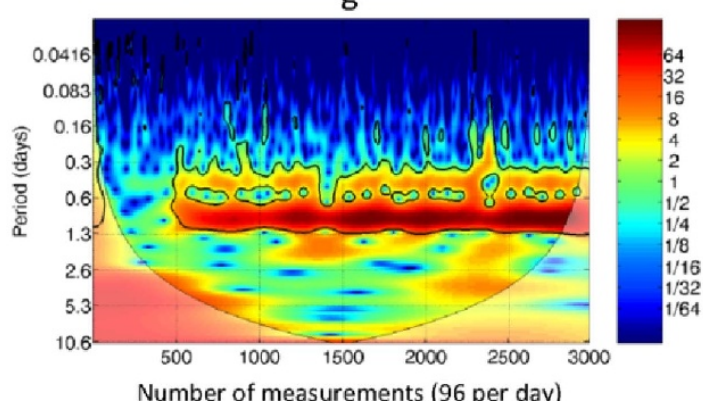

Number of measurements ( 96 per day)

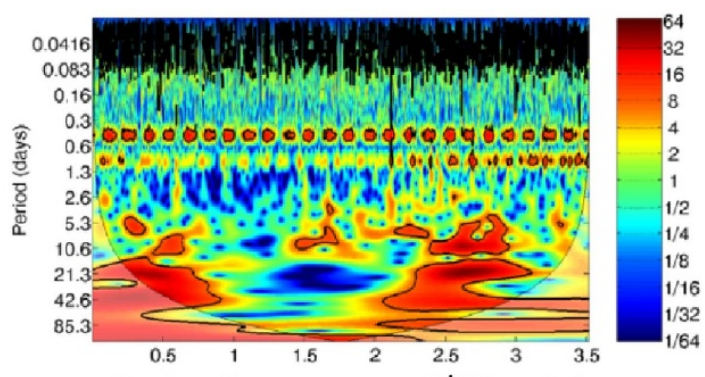

Number of measurements $\times 10^{4}$ (96 per day)

b

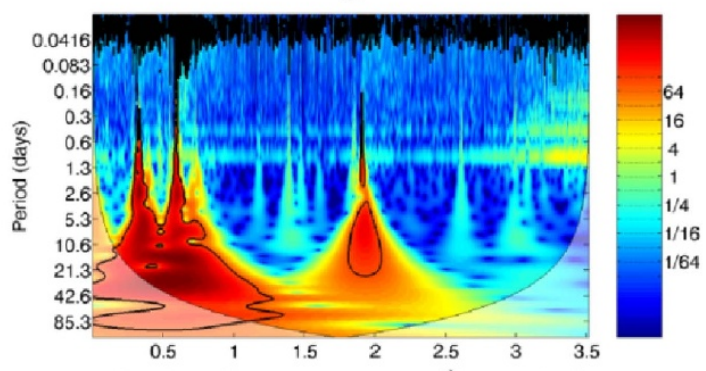

Number of measurements $\times 10^{4}$ (96 per day)

d

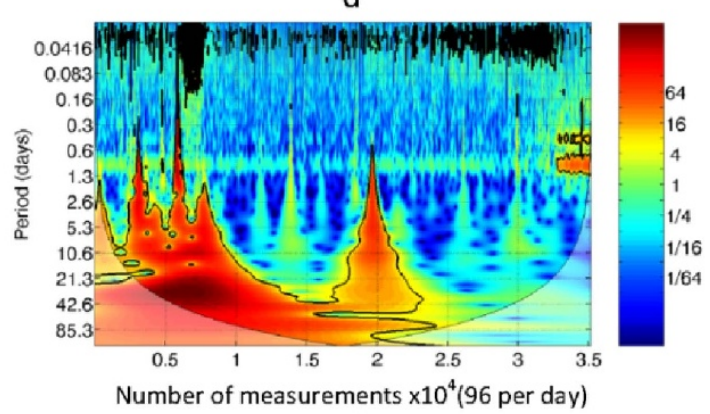

$f$

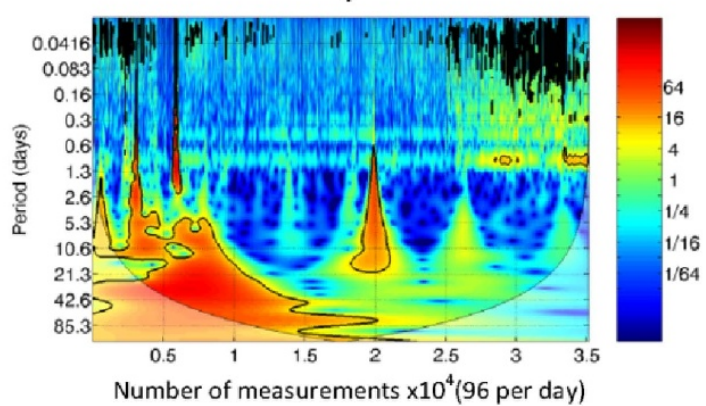

$\mathrm{h}$

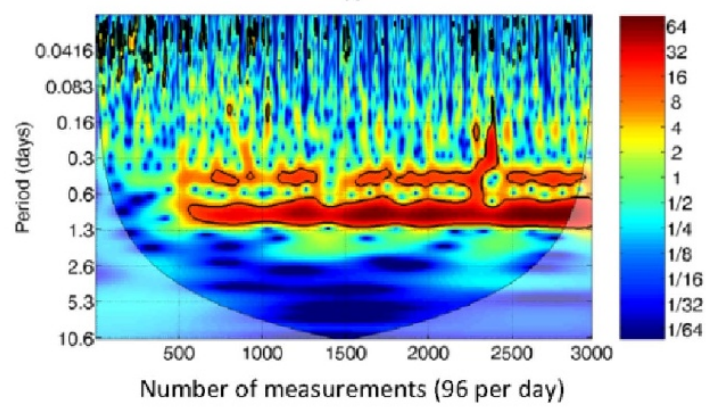

j

Figure 8 The presence of the M2 signal in Bogan River and Trangie at Dandaloo piezometer: $(a, b)$ - scalograms of the Trangie at Dandaloo piezometer during 2012 for raw data and, respectively, simple derivative data; (c, d) - scalograms of the raw and, respectively, simple derivative time series of Bogan River at Dandaloo during 2012; (e, f) - scalograms of the raw and, respectively, simple derivative time series of Bogan River at Neurie Plains during 2012; (g, h) - scalograms of the raw and, respectively, simple derivative time series of Bogan River at Nyngan during 2012; (i, $j$ ) - scalograms of the raw and, respectively, simple derivative time series of Bogan River at Neurie Plains during December 2012. 

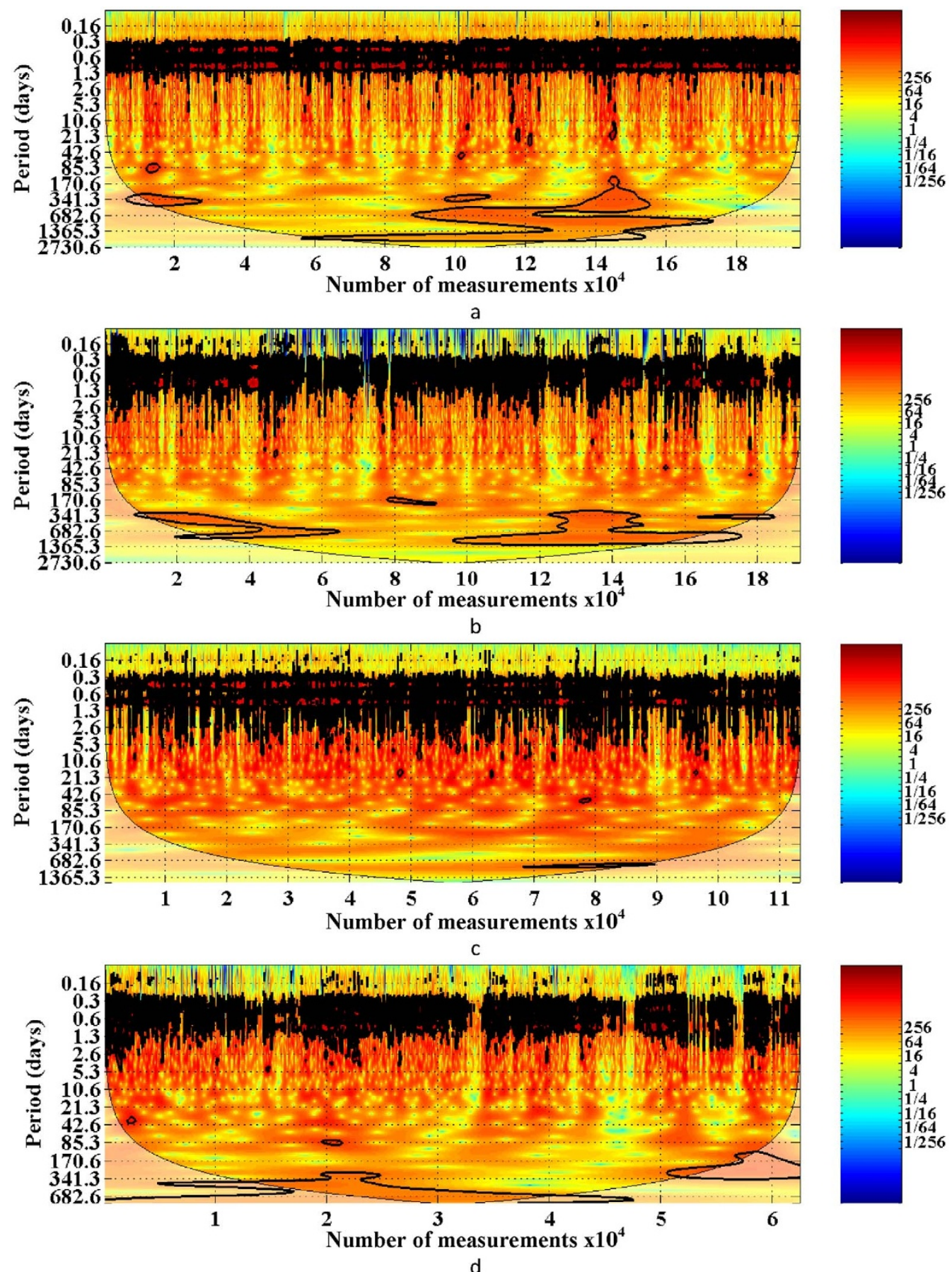

Figure 9 | CWT scalograms of: (a) - Medina River (October 1990-December 2013); (b) - Nueces River (October 1991-December 2013); (c) - Panther Brook at Spring (October 1999-December 2013); (d) - Las Moras Springs (October 2003-December 2013).

M2 signal amplitude found in Australian rivers when it is compared to the M2 signal in USGS rivers (higher accuracy means higher detection chances - Tables 1 and 2). Also, the hydrologists' custom of using river discharge instead of river water level can be an explanation of the late discovery of the M2 signal in inland rivers.

\section{Discussion}

Some of the studied gauges ( 5 - on Medina, Leona and Nueces rivers, Las Moras Springs and White River) are placed in areas rich in limestone/dolomite rocks. For example, the piezometer in Medina catchment is completed in "Edwards and Associated Limestones" (218EDRDA) local aquifer, while the piezometer near Leona River is completed in the limestone and shale of the Mc Knight Formation.
Limestone and dolomite are often involved when the tidal effect is studied for groundwater because of the good tidal response $\mathrm{e}^{14,18,21}$. Rocks have different responses to tidal strain ${ }^{22}$, especially if they have a secondary porosity, which make the formation more compliant to tidal stress depending on the position of the fractures and faults relative to the directions of the imposed stress ${ }^{23-25}$. The tidal strain differentiation which induces horizontal groundwater flow is clearly evident when dolomite is implied ${ }^{14}$.

Medina, Leona, Comal, Nueces rivers and Las Moras Springs are linked to the same groundwater source: The Edwards-Trinity Aquifer. The selected Nueces, Comal and Leona river gauges have strong M2 signal, being placed in the headwaters area of the homonymous rivers, while the downstream gauges, being placed in 
Table 2 | Details of the secondary gauges

\begin{tabular}{|c|c|c|c|}
\hline no. & Code and name & a.s.l. $(\mathrm{m})$ & ampl. $(\mathrm{m}) *$ \\
\hline \multicolumn{4}{|c|}{ Groundwater } \\
\hline 1 & USGS 291136099375801 YP-69-51-606 (E. Uvalde 3), TX, USA & 267.5 & 0.02 \\
\hline 2 & USGS 301948095290004 TS-60-45-4 14 (City of Conroe Piezometer No. 3), TX, USA & 80 & 0.02 \\
\hline 4 & GW039001 The Ranch, NSW, Australia & 12 & 0.01 \\
\hline 5 & GW030201 Trangie at Dandaloo P2, NSW, Australia & 210 & 0.02 \\
\hline \multicolumn{4}{|c|}{ 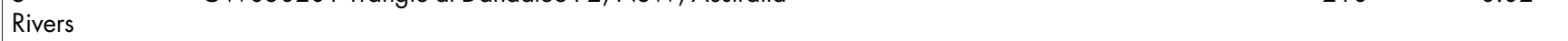 } \\
\hline 9 & 421138 Bogan Rv. at Nyngan NSW, Australia & 170 & 0.002 \\
\hline
\end{tabular}

*rounded average values of the observed maximum heights of semidiurnal peaks.

intensive agricultural or highly populated areas (Uvalde and New Braunsfels cities and downstream) and under a persistent day/night diurnal cycle, lose their semidiurnal oscillation. It is also important to notice that the hydronym "spring" occurs in 2 names of the selected gauges, indicating the important role of groundwater. Also, it was a frequent hydronym in the name of the gauges that have not passed the anthropic influences filter. Springs or the hydronym of "spring"। "springs" occur in the immediate vecinity $(<10 \mathrm{~km}$ radius) of 11 gauges (from 17; this information is based on found hydronyms, but the incidence is probably higher): the gauges on Panther Brook, Comal, Leona, Medina, White, Bogan rivers and Las Moras Springs.

The Las Moras Springs gauge measures water levels at springs under artesian pressure. There are temporary artesian springs in the Bega and Macquarie catchments. It is probable that the main mechanism of exporting M2 signal from groundwater to rivers is the following: at new and full moons, the lunar tidal forces are stronger and, when the Moon lies at Zenith and Nadir, the aquifers are less compressed, the groundwater level lowers and the groundwater input into rivers is smaller; when the moon is at horizon, the aquifers are more compressed and the increase in groundwater level can cause an increased groundwater discharge into rivers.

Another mechanism was revealed by Medina River. At San Antonio gauge, Medina River loses water into Balcones Fault Zone (according to USGS) and it is most likely that the river loses less water when the Moon is at horizon. Therefore, the groundwater output mechanism is replaced by a groundwater input one.

A good correlation between the Moon position and the M2 oscillations of the stream water level is generally not to be expected because phase-shifts occur in mid-continental groundwater due to the different elasticity of rocks and, thus, due to their different response to tidal force $e^{14,24,26}$. Shifts between groundwater oscillations and tides can be explained sometimes by very particular $\operatorname{sites}^{27}$ and by leakage in a confined-unconfined aquifers system ${ }^{19}$. The amplitude of the semidiurnal tidal fluctuation in groundwater increases with the increasing depth of the aquife ${ }^{28}$ and complicates the tidal response of the multi-layered aquifers. Time lags between the signal production in a river (on geology with good tidal response) and the arriving of that signal at a measuring point with different geology and with varying streamwater velocity can occur.

Table 3 | Water level correlation coefficients of Medina River at San Antonio gauge and Edwards piezometer

\begin{tabular}{lcccccc} 
& $\mathrm{P}$ & $\mathrm{K}$ & $\mathrm{S}$ & s.c.P & s.c.K & s.c.S \\
\hline June 2013 & -0.43 & -0.37 & -0.51 & -0.51 & -0.4 & -0.51 \\
July 2013 & -0.31 & -0.22 & -0.3 & -0.56 & -0.44 & -0.55 \\
August 2013 & -0.5 & -0.35 & -0.5 & -0.61 & -0.45 & -0.58
\end{tabular}

P, K, S - Pearson, Kendall and Spearman coefficients, respectivelly; s.c. - scaled correlation.
Concerning the amplitude of M2 orthotidal signal in streamwater, it varies depending on river gauge position relative to signal generation area, geology and perturbing factors, such as rainfall. It is very difficult to establish minimum or average values for the same river because the signal strength varies depending on yet unquantified factors and because the signal is sometimes buried in red noise or included as inflection in the diurnal signal. Average maximum values can be found in Tables 1 and 2, which suggest strong aquifer discharges for the monitored gauges.

The M2 signal in rivers is discontinuous and often hard to detect. The signal discontinuity is caused mainly by geological and meteorological factors. The best analysis windows when using wavelets ranges from 3000 to 300000 measurements (at 96 measurements per day).

The number of inland gauges certainly having M2 orthotidal signal in the studied area is most probably greater than discovered in this paper with our selection analysis because the primary gauge selection was based only on gauges having possible semidiurnal oscillations for a limited window analysis of 7 consecutive days in JuneJuly 2011. Moreover, the human intervention on some rivers can delete or alter the weak M2 signal. When M2 is strong in some inland streamflows, it can have important influences on ecosystem dynamics of the riparian areas.

Further studies must quantitatively establish the particular conditions generating the M2 orthotidal signal and its characteristics. Statistical studies must establish if the wet/dry seasons imply stronger/weaker M2 signal (depending on the antagonistic effects of the high water episodes and the strong aquifer discharge under lunar tides when it is charged by rains), if there exists any climate-dependent orthotidal M2 influence of groundwaters on rivers, if the lunar influence on rivers through precipitation is strengthening or weakening the lunar influence through groundwater, if the time lag between the rainy season and the maximum seasonal discharge of the inland and coastal aquifers ${ }^{29}$ diminishes or amplifies the intensity of the orthotidal signal of the rivers, if the orthotidal M2 will be in phase, anti-phase or out of phase with the tidal M2 in coastal areas, if there is any influence of the geographical latitude on the orthotidal M2 signal strength in rivers or if the lunar phases create stronger/ weaker orthotidal M2 signal.

\section{Methods}

For analysing time series, we used the CWT analysis, which is a powerful tool in detecting signals in hydrological time series (when compared to FFT analysis); the wavelet analysis is described as a microscope of signals ${ }^{30}$. We extracted the GWS values of river data by using the methodology described by Labat ${ }^{31}$. The PWC analysis reveals the common periodicities of 2 time series after removing the influence of a selected periodicity; it is similar to partial correlation and it was applied by using the methodology of $\mathrm{Ng}$ and $\mathrm{Chan}^{32}$. Morlet wavelet was used as mother-wavelet for the CWT and PWC analyses because it is well-suited and preferred by authors studying the hydrological periodicities if they use the wavelet analysis ${ }^{33}$. Morlet wavelet is a nonorthogonal wavelet function and provides a better balance between frequency and 
time localizations when compared to orthogonal wavelet functions. It provides a more realistic image of the oscillations in data with nonstationary processes (such as river water level $)^{35}$. The scalograms in this study have areas enclosed by thick black contours which represent the 0.95 confidence level against AR1 red noise (specific to river time series); the confidence level verification against red noise used the Monte Carlo test; everything was done in accordance to the methodology of Grinsted et al. ${ }^{34}$. The wavelet coefficients at the edges of scalograms are affected by edge effects that alter the results, generating a cone of influence ${ }^{35}$; the altered results are showed by using a lighter shade for the colours of the power spectrum. The wavelet coherence analysis (WTC) analysis was used according to the methodology of Grinsted et al. ${ }^{34}$. WTC scalograms include phase arrows between the compared river/groundwater time series (pointing right means in-phase; left: anti-phase; down: series 1 leads series 2 by $\left.90^{\circ}\right)^{34}$. The long time series used in Figure 9 and Supplementary Fig. 6 required special treatment in order to ensure a greatly denoised data: the hourly raw data was detrended, then the simple derivative was applied; the resulting data (containing positive and negative values) was treated against high waters episodes by applying a high waters filter which proportionally reduces the high waters values to values within the range of $95 \%$ of data around the time series mean ( $95 \%$ is replaced by $85 \%$ for Clear Fork Trinity and by $75 \%$ for Blue River due to the existence of more important episodes of high waters); a smoothing of each 6 consecutive values ( $1 / 4$ of a day) is applied twice and then a median filtering of each 6 consecutive values is applied in order to enhance the slopes of the remaining dominant peaks. A rectified CWT analysis was applied in order to correct the power loss at higher frequencies, according to the method described by $\mathrm{Ng}$ and $\mathrm{Chan}^{32}$.

1. Cerveny, R. S., Svoma, B. M. \& Vose, R. S. Lunar tidal influence on inland river streamflow across the conterminous United States. Geophys. Res. Lett. 37, L22406 (2010).

2. Gribovszki, Z., Szilágyi, J. \& Kalicz, P. Diurnal fluctuations in shallow groundwater levels and streamflow rates and their interpretation - A review. J. Hydrol. 385, 371-383 (2010)

3. Callede, J. Oscillations journalières du débit des rivières en l'absence de precipitations. Cah. ORSTOM, sér. Hydrol. 14, 219-283 (1977).

4. Lundquist, J. D. \& Cayan, D. R. Seasonal and spatial patterns in diurnal cycles in streamflow in the western United States. J. Hydrometeor. 3, 591-1603 (2002).

5. Peters, N. E., Freer, J. \& Aulenbach, B. T. Hydrological dynamics of the Panola Mountain research watershed, Georgia. Ground Water 41, 973-988 (2003).

6. Lambert, W. D. Report on earth tides. U.S. Coast Geodet. Surv. 223, 24 (1940).

7. Robinson, T. W. Earth tides shown by fluctuations of water levels in wells in New Mexico and Iowa. Trans. AGU 20, 656-666 (1939).

8. Meyer, F. W. Evaluation of hydraulic characteristics of a deep artesian aquifer from natural water-level fluctuations, Miami, Florida. Florida Bureau of Geology Report of Investigations 75, 32 (1974).

9. Melchior, P. The Tides of the Planet Earth. 2nd edn (Pergamon Press, Oxford, 1983).

10. Jacob, C. E. On the flow of water in an elastic artesian aquifer. Trans. AGU 21, 574-586 (1940).

11. Wesseling, J. Transmission of tidal waves in elastic artesian basins. Neth. J. Agric. Sci. 7, 22-32 (1959).

12. Bredehoeft, J. D. Response of well-aquifer systems to earth tides. J. Geophys. Res. 72, 3075-3087 (1967).

13. Van der Kamp, G. \& Gale, J. E. Theory of earth tide and barometric effects in porous formations with compressible grains. Water Resour. Res. 19, 538-544 (1983).

14. Gieske, A. \& De Vries, J. J. An analysis of earth-tide-induced groundwater flow in eastern Botswana. J. Hydrol. 82, 211-232 (1985).

15. Acworth, R. I. \& Brain, T. Calculation of barometric efficiency in shallow piezometers using water levels, atmospheric and earth tide data. Hydrogeol. J. 16, 1469-1481 (2008).

16. Kümpel, H. J. Verformungen in der Umgebung von Brunnen, Habilitationsschrift für das Fach Geophysik an der Mathematisch-Naturwissenschaftlichen Fakultät der Christian-Albrechts-Universität Kiel, Germany (1989).

17. Camuffo, D. Lunar influence on climate. Earth, Moon, and Planets 85-86, 99-113 (2001)
18. Merritt, M. L. Estimating hydraulic properties of the Floridan aquifer system by analysis of earth-tide, ocean-tide, and barometric effects, Collier and Hendry Counties, Florida. US Geol. Surv. Water Resour. 03-4267 (2004).

19. Jiao, J. J. \& Tang, Z. H. An analytical solution of groundwater response to tidal fluctuation in a leaky confined aquifer. Water Resour. Res. 35, 747-751 (1999).

20. Zimmerman, J. K. H., Letcher, B. H., Nislow, K. H., Lutz, K. A. \& Magilligan, F. J Determining the effects of dams on subdaily variation in river flows at a wholebasin scale. River Res. Applic. 26, 1246-1260 (2010).

21. Hobbs, P. J. \& Fourie, J. H. Earth-tide and barometric influences on the potentiometric head in a dolomite aquifer near the Vaal River Barrage, South Africa. Water Research Commission, Pretoria, South Africa 26, 353-359 (2000).

22. Rojstaczer, S. \& Agnew, D. C. The influence of formation material properties on the response of water levels in wells to earth tides and atmospheric loading. J. Geophysics Res. 9, 12403-12411 (1989).

23. Hanson, J. M. \& Owen, L. B. Fracture orientation analysis by the solid earth tidal strain method. paper presented at The 57th Annual Fall Technical Conference and Exhibition of the Society of Petroleum Engineers of AIME, American Institute of Mechanical Engineers, New Orleans, Louisiana (1982).

24. Bower, D. R. Bedrock fracture parameters from the interpretation of well tides. J. Geophys. Res. 88, 5025-5035 (1983).

25. Hsieh, P. A., Bredehoeft, J. D. \& Rojstaczer, S. A. Response of well-aquifer systems to earth tides: Problem revisited. Water Resour. Res. 24, 468-472 (1988).

26. Morland, L. W. \& Donaldson, E. C. Correlation of porosity and permeability of reservoirs with well oscillations induced by earth tides. Geophys. J. R. Astron. Soc 79, 705-725 (1984)

27. Maas, C. \& De Lange, W. J. On the negative phase shift of groundwater tides near shallow tidal rivers - The Gouderak anomaly. J. Hydrol. 92, 333-349 (1987).

28. Senitz, S. Untersuchung und Anwendung kurzperiodischer Schwankungen des Grundwasserspiegels in Thüringen. Grundwasser 4, 163-173 (2001).

29. Michael, H. A., Mulligan, A. E. \& Harvey, C. F. Seasonal oscillations in water exchange between aquifers and the coastal ocean. Nature 436, 1145-1148 (2005).

30. Sang, Y.-F., Wang, D., Wu, J.-C., Zhu, Q.-P. \& Wang, L. The relation between 'periods' identification and noises in hydrologic series data. J. Hydrol. 368, 165-177 (2009).

31. Labat, D. Cross wavelet analyses of annual continental freshwater discharge and selected climate indices. J. Hydrol. 385, 269-278 (2010).

32. Ng, E. K. W. \& Chan, J. C. L. Geophysical applications of partial wavelet coherence and multiple wavelet coherence. J. Atmos. Oceanic Technol. 29, 1845-1853 (2012).

33. Labat, D. Recent advances in wavelet analyses: Part 1. A review of concepts. J. Hydrol. 314, 275-288 (2005).

34. Grinsted, A., Moore, J. C. \& Jevrejeva, S. Application of the cross wavelet transform and wavelet coherence to geophysical time series. Nonlinear Proc. Geoph. 11, 561-566 (2004).

35. Torrence, C. \& Compo, G. P. A practical guide to wavelet analysis. Bull. Am. Meteor. Soc. 79, 61-78 (1998).

\section{Acknowledgments}

Wavelet coherence software was provided by A. Grinsted.

\section{Author contributions}

A.-E.B. studied the hypothesis and wrote the manuscript.

\section{Additional information}

Supplementary information accompanies this paper at http://www.nature.com/ scientificreports

Competing financial interests: The authors declare no competing financial interests.

How to cite this article: Briciu, A.-E. Wavelet analysis of lunar semidiurnal tidal influence on selected inland rivers across the globe. Sci. Rep. 4, 4193; DOI:10.1038/srep04193 (2014).

This work is licensed under a Creative Commons AttributionNonCommercial-NoDerivs 3.0 Unported license. To view a copy of this license, visit http://creativecommons.org/licenses/by-nc-nd/3.0 